\title{
Numerical Investigation on the Influence of Web Opening on the Structural Behaviour of RC Deep Beams
}

\author{
Abdulnasser Mohammed Abbas ${ }^{a *}$ \\ ${ }^{a}$ Civil Engineering Department, Engineering College, Basrah University, Basrah, IRAQ
}

\section{A R T I C LE I N F O}

\section{Article history:}

Received 24 August 2019

Received in revised form 29 September 2019

Accepted 10 October 2019

\section{Keywords:}

Deep beams

Web openings

Special reinforcements

ABAQUS

\begin{abstract}
A B S T R A C T
Nowadays, the deep beams become utilized more in a considerable number of structures. It is necessary sometimes to introduce a hole within the web of the beam as a pipe or a duct for many purposes such as water supply, sewage, electricity, air conditioning, and computer network. In this study, a deep beam sample taken from a past experimental study is numerically analysed using a three-dimensional finite element model. ABAQUS tools are used to simulate the whole FE models. The dimensions of the considered deep beam are $820 \times 400 \times 180 \mathrm{~mm}$, with two openings of a diameter $90 \mathrm{~mm}$ located at $200 \mathrm{~mm}$ from both of the ends. The proposed model and the experimental work have reasonably agreed with a difference of $2 \%$ in mid-span deflection. Furthermore, special reinforcements of $12 \mathrm{~mm}$ bar diameter are offered to the original FE model around the holes in two types, Z-shape and circular, to improve the structural behaviour of the deep beam and to minimize the crack concentrations in these zones. The gained results show that the additional reinforcement minimizes the mid-span deflection of the deep beam. As compared with the original proposed FE model, the Z-shape decreases the deflection by $44.9 \%$ while the lowering in the defection of the circular shape is $9.4 \%$. Moreover, the concentration of stresses and cracks that gained from using the Z-shape reinforcement model found to be lower than those induced in the circular reinforcement model.
\end{abstract}

\section{Introduction}

The essential definition of the deep beams in the ACI 318- 14 code [1], can be summarized as a member made from reinforced concrete and loaded on a single front, while supports lie on the other front. In the meantime, the clear span to the overall depth ratio must equal or not exceed four, Also, it is necessary to mention that the concentrated loads must be applied within $2 \mathrm{~h}$ distance from the support face. While the hypothesis of Bernoulli for (slender) beams which states that, plane sections continue plane is not applied to the deep beams, because the strain distribution on the beam is nonlinear, and this led the deep beam to behave as a restricted arch. Deep beams are utilized vastly in constructions like floor diaphragms, foundation pile caps, shear walls, and wall footings [2]. Moreover, during the last few decades, deep beams are used extensively in high rise buildings [3]. The failure mode of deep beams depending on the geometry of these members, and it is utterly dominated by shear failure instead of flexural. Therefore, the shear strength factor becomes highly crucial in the concrete design of deep beams [4]. In modern structures, it is necessary to install numerous

\footnotetext{
* Corresponding author

E-mail address: nasser21272@gmail.com (Abdulnasser M. Abbas)
} 
ducts and pipes for air conditioning, water supply, electricity, sewage, and computer network. These ducts or pipes are usually laying beneath the beam soffit, and due to aesthetical causes, they covered by a pseudo roof. On the other hand, there is another configuration that could be made to make these pipes and ducts pass-throughout slots created in the beams. This configuration is considered as a compact and economical design of deep beams [4]. Indeed; these cross slots (pipes and ducts) within the web of the beam will minimize the gross stiffness of such beams; and then, may cause high deformations due to resulting service loads that produced from the internal forces redistribution which lead to minimizing the beam ultimate strength to a critical stage [5]. The existence of a hole in the deep beams produces a geometric cut-out in these members, and stresses will be distributed nonlinearly through-out the beam depth [6]. Unfortunately, there are no specifications included in the AC1318M-11 [7] to the deep beam web openings. Therefore, there is a great need for a uniform, accurate and safe design methodology for this issue. Furthermore, a special rebar configuration should be provided adjacent to or around to the hole, with an adequate amount to avoid possible beam failure and to keep crack under control [8]. Yang et al. [9] studied the concrete strength diversity influence on extreme strength of shear, and they found that it was considerably lower in deep beams that having holes rather than deep beams without holes. Moreover, the concrete strut compressive strength for a deep beam with holes rise at a minimum rate when the concrete strength increased gradually. Yang et al. [10], conducted a study on the deep reinforced concrete beams that have openings. In this investigation, the quantity of sloping rebar and the opening breadth was considered as the prime variables. A proposed to the influence of the inclined rebar quantity and the hole size was done on the beam's structural behaviour. The shear strength and width of the diagonal crack for the tested beams was noticed to be considerably dependent on the active inclined factor of the test specimen reinforcement, which is varied from 0 to 0.318 . When this operator rise, the width of the diagonally inclined crack and its rate will reduce, then, the strength of shear for the tested beams will improve. Maaddawy and Sherif [11] investigated the possibility of utilizing the exterior bind of the composite CFRP (carbon fibre reinforced polymer) sheets just as a reinforcement manner to enhance the efficiency of deep reinforced concrete beams with holes. The parameters that considered are the existence of the CFRP plates, location and size of the opening. The deep reinforced concrete beams structural response with the opening existence mainly dependent on the interruption grade to the path of the natural load. The CFRP plates which are bonded externally around the holes increase the enhancement of the deep beam shear strength. The gained strength due to the utilizing of the CFRP plates is within 35-73\%. In 2012, Campione and Mianfo [12] found that the load of the first crack and failure mode influenced by the existence and location of the hole. For instance, if the hole located at the mid-span, the beam response does not influence, while if the hole is set inside the shear span, the capacity of load-carrying will minimize about $18-30 \%$. An investigation was conducted by Alsaeq [13] on the influence of the location and shape of the opening on the structural behaviour of the deep reinforced concrete beam, while the size of opening remains unchanged. Finite element analysis was carried out by using ANSYS12.1. The ultimate deep beam strength with the existence of a web opening determined by the mentioned numerical method appearing adequate compatibility with the experimental outcomes. The gained results indicate that the opening position has a great influence on the strength of the member more than its shape. Moreover, the placement of the hole adjacent to the upper deep beam corners may enhance the strength two times. On the other hand, when a narrow opening with a rectangular shape used horizontally along the sides, it may save more than $40 \%$ of the deep beam structural strength.

An experimental investigation was done by Sheelu and Afia, [14], on the deep reinforced concrete beams with the existence of a circular hole. Eight deep beams with $820 \mathrm{~mm}$ length, $400 \mathrm{~mm}$ depth and $180 \mathrm{~mm}$ width having a single opening, double openings and a control specimen were tested by applying a 50 Ton point load. The considered parameters are; the size and position of the opening, provided web reinforcement, the presence, and percentage of the CFRP sheets. The whole tested beams are failed by compression diagonal shear. In general, the cracks are initiated as flexural cracks, and they are absent when the load is equal to or below $45 \%$ from the ultimate load. A two opening beam holds about $79 \%$ of the ultimate load, while in the case of a beam with a single central opening, the capacity of the load was unchanged. Beams that reinforced by fiber exhibited no change in the load-carrying capacity, however, when a comparison is made with specimens that having no fiber, the existence of such fiber reduces the crack width. Ragheed et al. [15] investigate eight concrete deep beams made from reactive powder, which analyzed nonlinearly using ANSYS V.15 tool. The outcomes obtained theoretically from the simulated models were compared with the results that gained experimentally. The parametric study consists of three parts that were done by varying the opening size, opening position, and configuration systems of CFRP. The comparison demonstrates that the results obtained from the ANSYS are identical, to some extent, with the experimental outcomes, and the variation of the ultimate load is approximately below 7.5\%. Ammar and Maha [16] presented an experimental and theoretical study on the RC deep beam to investigate the overall shear behaviour. A concrete hybrid strength technique was employed, in which normal (ordinary) strength was used in the tension region, while high strength was utilized in the compression region. Nine samples of deep beams were made and loaded by two concentrated loads. Two groups of deep beams were used to investigate many parameters, such as the influence of the existence of the web reinforcement, the deflection, the pattern of cracks, the cracking load, the frailer modes, and the ductility. Moreover, a compression made between both of the experimental and analytical outcomes, which revile an adequate agreement to the response of the load-deflection relationship. The optimum variation rate in the starting crack and the ultimate loads was found to be $13 \%$ and $9.6 \%$, respectively.

In the present work, FE analysis will be made using the ABAQUS tool to simulate RC deep beam with two openings, the taken sample of the deep beam is mentioned above as an experimental work done by Sheelu and Afia [14]. A comparison will conduct between the results obtained by the FE simulation and the experimental outcomes to examine the compatibility of the proposed FE model with the experimental one. Moreover, a special reinforcement around the two holes is provided to enhance the structural behaviour of the deep beam.

\section{Beams Modelling}

The proposed numerical model depends on an experimental work conducted by Sheelu and Afia, [14]. The considered dimensions of the deep beam were $820 \mathrm{~mm}$ (length), $400 \mathrm{~mm}$ (depth) and 180 (width), with two 90 $\mathrm{mm}$ diameter circular openings at $200 \mathrm{~mm}$ from both sides of the beam. The deep beam is subjected to a single point load as shown in Fig. 1. The modulus of elasticity for concrete determined according to ACI 318M [1], which is defined as $\mathrm{Ec}=4700 \sqrt{\mathrm{fc}^{\prime}}$ (MPa). Brief details for the steel reinforcement and concrete compressive strength are shown in Table 1. 


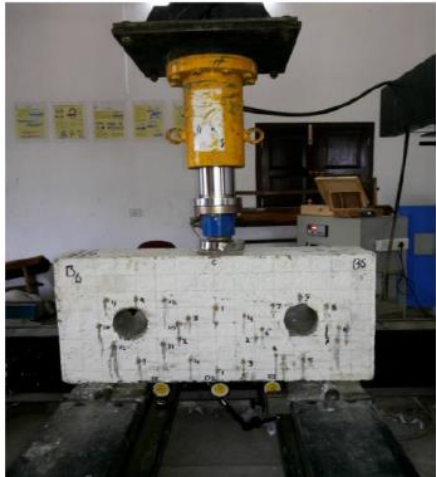

Figure 1. Experimental settings [14]

Table 1. Details of the deep beam [14]

\begin{tabular}{lll}
\hline Item & Types of Reinforcement & \multicolumn{1}{c}{ Details } \\
\hline \multirow{3}{*}{ Rebar } & Main Rebar & $4 \# 12 \mathrm{~mm}$ bottom \\
& & $2 \# 8 \mathrm{~mm}$ top \\
\cline { 2 - 3 } & Stirrups & $8 \mathrm{~mm} \mathrm{@} 200 \mathrm{~mm} \mathrm{c} / \mathrm{c}$ \\
\hline Concrete & compressive strength (cube) & $38.2 \mathrm{MPa}$ \\
\hline
\end{tabular}

\section{Simulation of Numerical (FE) Model}

To imitate the deep reinforced concrete beam numerically in ABAQUS software, the elements of the member (concrete and rebar) should be modelled accurately in a three-dimensional environment. First of all, the units of the input data for the proposed model must set to be harmonious (there is no compact system for units in ABAQUS) [17]. The deep beam is loaded by a single concentrated load at mid-span [14], therefore, steel plates are used in the model to dispense stresses on a wider region. These plates are placed over the mid-span of the deep beam as a loading plate, and at the bottom as supports at both sides. The supports of the deep beam are considered as a roller and pin in the proposed model.

Then, stress 3-D elements are used to the concrete part, where suitable integration rules are supplied for such elements depending on the experimental response of the sample. Therefore, brick linear elements of 8 node (C3D8R) are utilized to imitate the concrete and the loading and supports steel plates. Plastic damage parameters have used to reflect the behaviour of the concrete [3]. The parameters used for concrete damage plasticity are exhibited in Table 2.

Table 2. Parameters of damage plasticity for concrete

\begin{tabular}{l|l}
\hline Item & Value \\
\hline Dilation Angle & 30 \\
Eccentricity & 0.1 \\
$\mathrm{~K}$ & 0.6667 \\
Viscosity parameter & 0.0001 \\
$f b_{0} / f c_{o}$ & 1.16 \\
\hline
\end{tabular}

The rebar is assumed to be able for transmission only an axial force, and the steel uniaxial stress-strain relationship is idealized using a bilinear curve, which is used to demonstrate the elastic-plastic behaviour together with the strain hardening. Moreover, to calibrate the plastic-damage pattern, the stress-strain relationship has presented as discreet stages, to the strength of compression and tension, for various concrete resistance that obtained from the uniaxial tests [18]. The concrete uniaxial compressive behaviour in ABAQUS is defined as stress versus inelastic strain relation [3] as shown in Fig. 2.

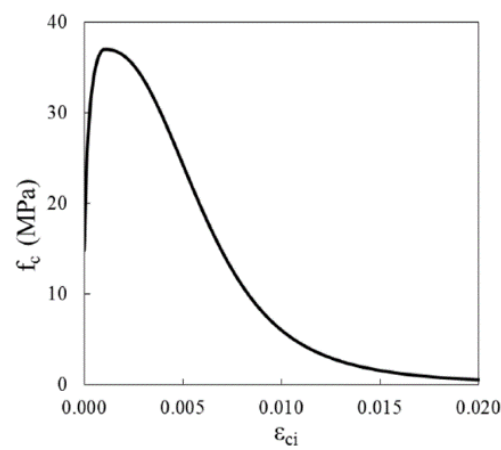

Figure 2. Uniaxial compressive stress-strain relation for concrete [3]

To consider the concrete degraded response, two uniaxial damage variables, compressive (dc) and tensile (dt), are set in the CDP (concrete damaged plasticity) model [3], as shown in Fig. 3.

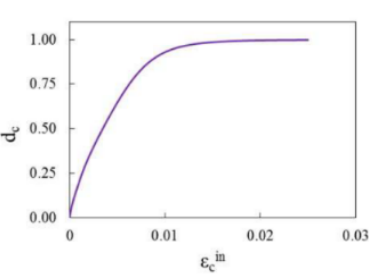

A

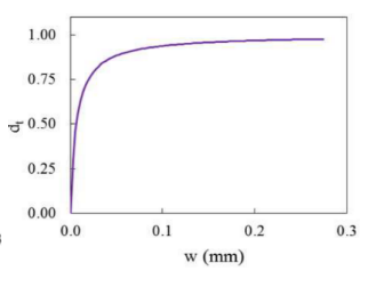

B
Figure 3. Concrete damage behaviours: A: Compressive damage, B: Tensile damage [3]

Finally, the concrete has meshed with different elements size; however, the size of $20 \mathrm{~mm}$ has demonstrated suitable outcomes, and when a smaller size of the element has used, the differences in results are not significant, see Fig. 4. The mechanical properties for concrete and steel are exhibited in Table 3.

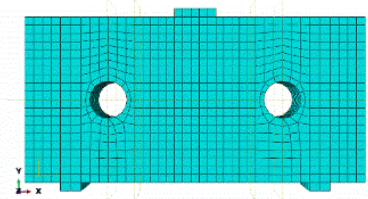

Figure 4. The Mesh utilized to imitate the deep beam

Table 3. The mechanical properties for concrete and steel

\begin{tabular}{cccc}
\hline Material & $\begin{array}{c}\text { Poisson's } \\
\text { Ratio }\end{array}$ & $\begin{array}{c}\text { Density } \\
\mathbf{K g} / \mathbf{m}^{\mathbf{3}}\end{array}$ & $\begin{array}{c}\text { Young } \\
\text { Modulus } \\
\text { MPa }\end{array}$ \\
\hline Concrete & 0.20 & 2400 & 25.754 \\
\hline $\begin{array}{c}\text { Steel } \\
\text { Rebar }\end{array}$ & 0.30 & 7800 & 210 \\
\hline
\end{tabular}

While the reinforcements and stirrups are modelled using (T3D2) 3-D linear truss element with 2-node, see Fig. 5. These elements are selected because the rebar has no high stiffness bending. Furthermore, it is assumed that perfect bond is held between the steel rebar and the concrete throughout the whole analysis. Then, an embedded constraint choice was picked to ensure that there is a full bond between the concrete and steel [19]. Corresponding to the approach of Von Mises, a bilinear pattern is taken to 
simulate the behaviour of steel, Rodríguez et al., 2012 [20]. Therefore, the material will behave linearly (elastic) until the stress reaches the yield point, then, after this stage, it will fully plasticize, as the constitutive pattern does not appear any stiffness.

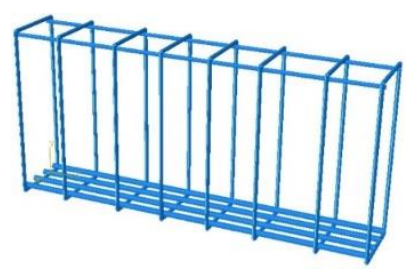

Figure 5. Representation of rebar and stirrups

\section{Results Discussion:}

\subsection{Model validation}

The performance of the proposed numerical model has examined by comparing the outcomes that earn from the FE model with those obtained experimentally by Sheelu and Afia in 2016 [14]. Fig. 6. shows the mid-span deflection for both the experimental and numerical works. A remarkable difference is found in the mid-span deflection between the experimental and the numerical results in the early stages of loading. However, as the load increased, the differences are gradually decreased to be approximately $2 \%$ which is considered reasonable to some extent.

The varying in the differences between the current work and the experimental one may come from the manner that used in applying the loads, the position of both load and supports, and finally, the assumptions that used in the construction of the numerical model. Therefore, the proposed model can be used to enhance the efficiency of the deep beam by adding a special reinforcement in the region around the openings.

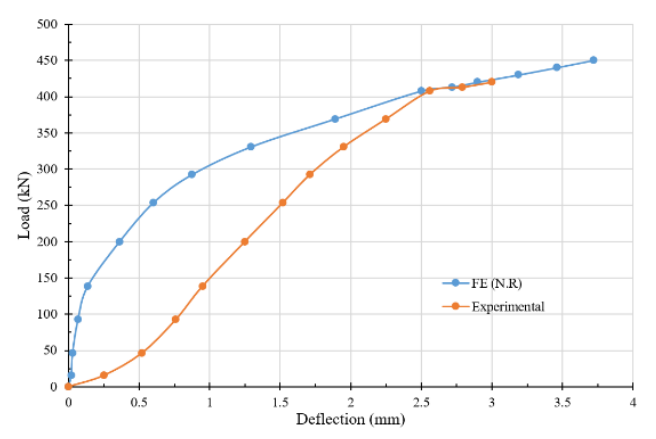

Figure 6. Deep beam mid-span deflection

\subsection{Special reinforcements around the holes:}

As previously mentioned, the FE model has suitably simulated the experimental sample taken from a past study [14]. However, it is beneficial to carry out more analysis to enhance the efficiency of the region adjacent to the openings. Actually; this is done via special reinforcements around the hole, as shown in Fig. 7. Two types of special reinforcement with a bar diameter of $12 \mathrm{~mm}$ have used, the first consists of three legs, two are parallel with the stirrups and tied with them well, while the middle leg has inclined in $45^{\circ}$ normal to the direction of cracks that may induce by the shear forces, see Fig. 7.A. However, the second type of reinforcement is circular and located around the hole, as shown in Fig. 7. B.

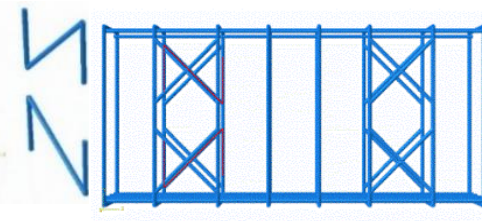

A

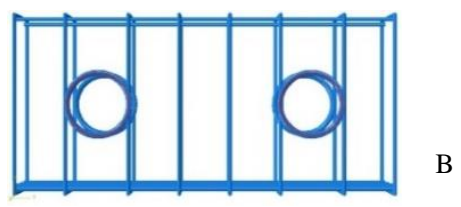

Figure 7. Special reinforcement around the openings

Two shapes of a special reinforcement are used to examine their influence on the structural behaviour of the considered deep beam. Comparisons have also made between the special reinforcement models with the original numerical one.

Fig. 8. shows the mid-span deflection for the proposed numerical three models, the original with No-Special Reinforcement (Nil), the Z-shape and the last is circular, both of the special reinforcements are made from bars of $12 \mathrm{~mm}$ diameter. Indeed, slight differences are observed in the mid-span deflection, for the whole three models, at a load equal or below $100 \mathrm{kN}$. However, as the load increased from $100 \mathrm{kN}$ up to $450 \mathrm{kN}$, the variation in deflection as compared between the (Nil) model and both the circular model and the Z-shape one will be lowered to $9.4 \%$ and $44.9 \%$ respectively, see Table 4.

In the meantime, when compared with the original model, the ultimate load will increase for the circular model and the Z-model to $6.3 \%$ and 10.7 $\%$ respectively, also see Table 4 . This indicates that the Z-shape reinforcement enhances the deep beam structural behaviour better than the circular shape.

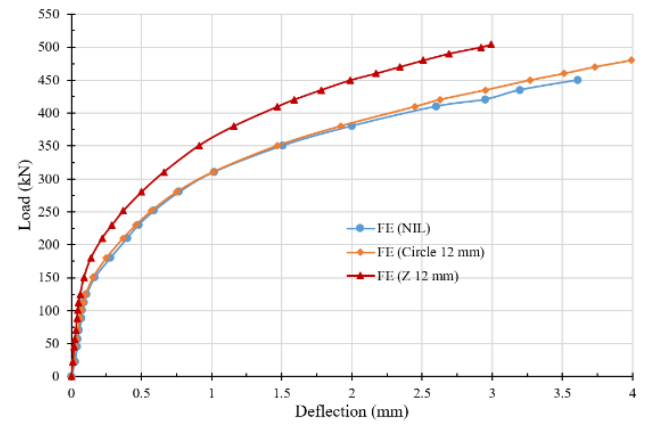

Figure 8. Mid-span deflection for the FE three models

Table 4. Mid-span and ultimate load comparison with nil special reinforcement model

\begin{tabular}{l|ll}
\hline Item & $\begin{array}{l}\mathrm{FE}(\text { circle } 12 \mathrm{~mm}) \\
\%\end{array}$ & $\begin{array}{l}\mathrm{FE}(\mathrm{Z} 12 \mathrm{~mm}) \\
\%\end{array}$ \\
\hline Deflection $(\mathrm{mm})$ & 9.4 (decrease) & 44.9 (decrease) \\
\hline Ultimate load $(\mathrm{kN})$ & 6.3 (increase) & 10.7 (increase) \\
\hline
\end{tabular}

Fig. 9. shows the variation profile for the vertical deflection and the deformation of the deep beam for the analysed three models. It can be seen, as mentioned above, that the differences appear clearly between the original model and the Z-shape model. 

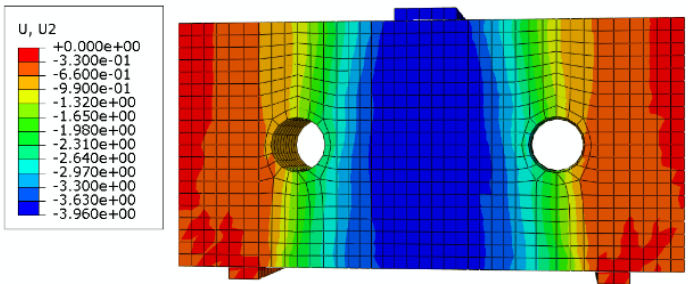

A
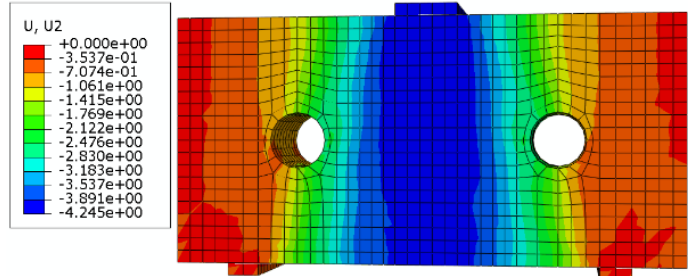

B

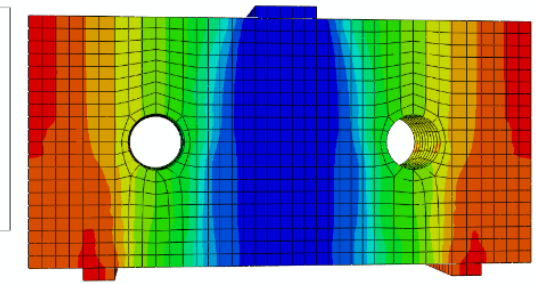

C

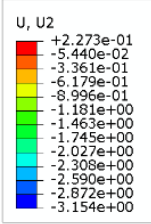

Figure 9. Y-direction displacements: (A) Nil; (B) CR12mm; (C) Z12 mm

Fig. 10. shows the Von-Mises stresses for the analysed three deep beam models. These figures exhibited significant lowering in the Von-Mises concentrations for the model that improved by adding a Z-shape special reinforcement around the holes. Moreover; the minimum value of these stress is $2.42 \times 10^{-01}$ for the deep beams that reinforced with circular rebar, while the lower value in the beam that strengthens with Z-shape is $1.05 \mathrm{x}$ $10^{-02}$. This indicates that improvement using $Z$-shape will induce lower stress.
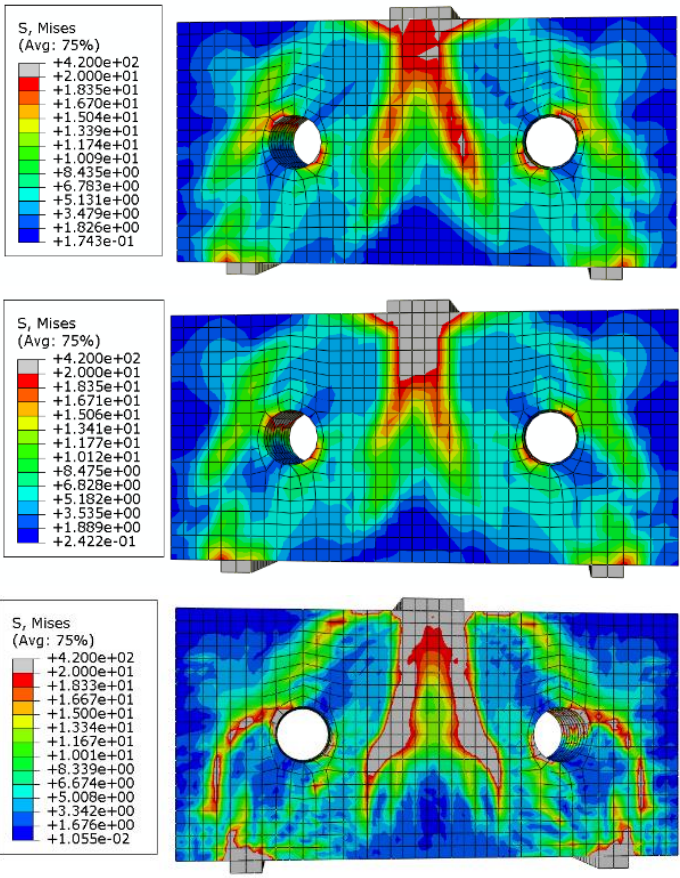

$\mathrm{C}$

Figure 10 - Von Mises stress: (A) Nil; (B) CR12mm; (C) Z12 mm
Fig. 11. presented the crack profile for the three analysed models. The crack path is diagonally moving from the loading zone to the supports region. Furthermore, the crack concentrations have lowered due to the employment of the special reinforcement around the holes. It can be seen, that the Z-shape model gives lower concentrations of the crack around the openings than the circular reinforcement model.
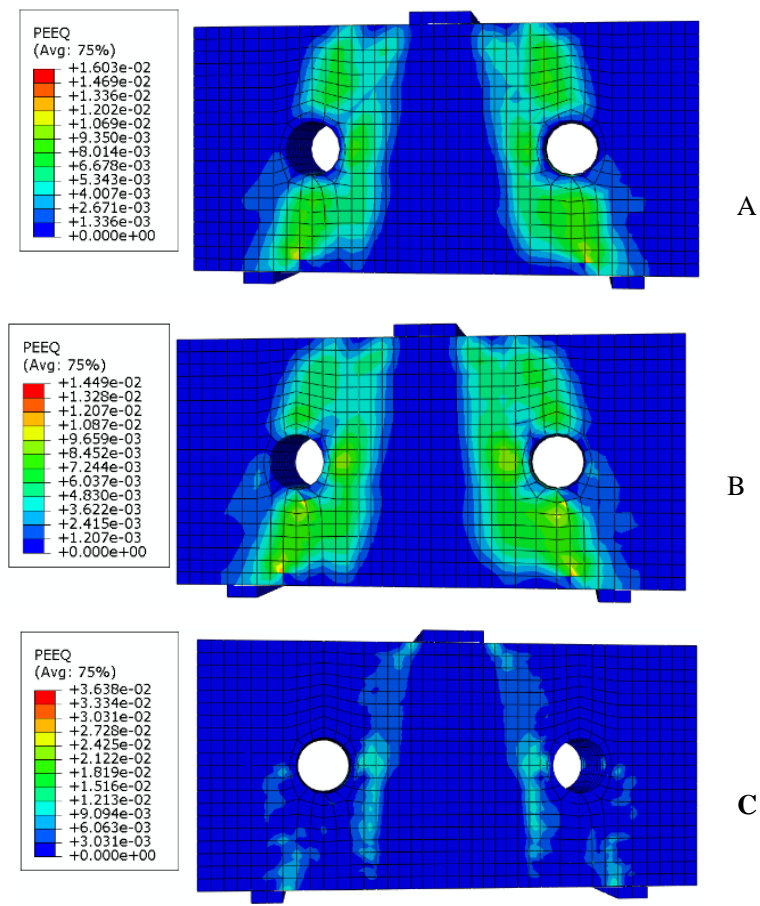

Figure 11 - Crack pattern: (A) Nil; (B) CR12mm; (C) Z12 mm

\section{Conclusions:}

Depending on the outcomes that determined from the numerically simulated three models, the following conclusions may be stated:

1. Differences are found, in the mid-span deflection, between the experimental results and the original FE model at the early stage of loading, however, as the load increases the variation will be minimized gradually to be approximately $2 \%$. This leads to a reasonable agreement, to some extent, between the proposed FE model and the experimental one.

2. The Z-shape reinforcement will lower the deflection by $44.9 \%$ as compared with the original model, while the circular reinforcement will lower the deflection by $9.4 \%$.

3. For the circular model, the ultimate load rises by $6.3 \%$, while for the Z-model the ultimate load increases by $10.7 \%$.

4. The Von-Mises stresses have been decreased by using special reinforcements. For a model that reinforced with a Z-shape around the holes, the minimum stress value is $1.05 \times 10^{-02}$, while for the deep beams with a circular rebar the lower value is $2.42 \times 10^{-01}$, which indicates that using of $\mathrm{Z}$-shape reinforcement will induce lower stress.

5. The crack concentrations have minimized due to the employment of the special reinforcement around the holes. In the meantime, it has recorded that the using of Z-shape reinforcement will induce lower crack concentrations around the holes. 


\section{REFERENCES}

[1] ACI 318-14, "Building Code Requirements for Structural Concrete", American Concrete Institute, 2014.

[2] Mohamed, A.R., Shoukry, M.S. and Saeed, J.M., "Prediction of the Behavior of RC Deep Beams with Web Openings Using the Finite Element Method", Alexandria Engineering Journal, 53, 2014, 329-339.

[3] Aydin Demir, Hakan Ozturk, Gokhan Dok, "3D Numerical Modeling of RC Deep Beam Behavior by Nonlinear Finite Element Analysis", Disaster Science and Engineering, 2016, p. 13-18, 2(1).

[4] Nishitha Nair, Kavitha P. E, "Effect of Openings in Deep Beams Using Strut and Tie Model Method", International Journal of Technical Research and Applications, Volume 3, Issue 5, September-October, 2015, PP. 59-62.

[5] Jin-Seop Lee and Sang-Sik Kim, "Shear Behavior of Reinforced Concrete Deep Beams with Web Openings", Journal of the Korea Concrete Institute, Vol. 13, No. 6, 2001, pp. 619-628.

[6] Guan, H. and Doh, J. H., "Development of Strut-and-Tie Model in Deep Beams with Web Openings", Journal of Advances in Structural Engineering, Vol. 10, No. 6, 2007, pp. 697-711.

[7] ACI Committee 318, "Building Code Requirements for Structural Concrete (318-11) and Commentary (318-11)", American Concrete Ins., Detroit, 2011.

[8] Mansur MA, Tan KH, Lee SL., "Collapse loads of RC beams with large openings”, ASCE Str. Eng. Journal, Vol.110, No. 11, 1984, pp. 2602-10.

[9] K Yanga, H Eunb and H Chungc, "The Influence of Web Openings on The Structural Behavior of Reinforced High- Strength Concrete Deep Beams" Engineering Structures, 2006, pp 1825-1834.

[10] K Yang, H Chung, and A F Ashour, "Influence of Inclined Web Reinforcement on Reinforced Concrete Deep Beams with Openings", ACI Structural Journal, Vol 104, 2007.

[11] T E Maaddawy and S Sherif, "FRP Composites for Shear Strengthening of Reinforced Concrete Deep Beams with Openings", Composite Structures,
Vol 89, 2009, pp 60-69.

[12] G Campione and G Minafò, "Behaviour of Concrete Deep Beams with Openings and Low Shear Span-to-Depth Ratio", Engineering Structures, Vol 41, 2012, pp 294-306.

[13] H M Alsaeq, "Effects of Opening Shape and Location on The Structural Strength of R.C. Deep Beams with Openings", International Journal of Civil, Environmental, Structural, Construction and Architectural Engineering, Vol 7, 2013.

[14] Er. Sheelu Mariam Punnoose, Er. Afia S. Hameed, "Experimental Study of Strengthening of RC Deep Beam with Web Opening”, International Journal of Innovative Research in Technology, Volume 3 Issue 4, September 2016.

[15] Ragheed Fatehi Makki, Ali Talib Jassem and Hayder Abd Al-latef Jassem, "Non-Linear Analysis of Reactive Powder Concrete (RPC) Deep Beams with Openings Strengthened by CFRP”, Al-Qadisiyah Journal for Engineering Sciences, Vol. 11, No. 2, 2018, pp 176- 196.

[16] Ammar Yaser Ali and Maha Ghazi Zghair, "Experimental Investigation and Nonlinear Analysis of Hybrid Reinforced Concrete Deep Beams", AlQadisiyah Journal for Engineering Sciences, Vol. 8, No. 2, 2015, pp 99119.

[17] ABAQUS, “ABAQUS/standard version 6.10 user's manuals: Volume I-III”, Hibbitt, Karlsson, and Sorenson, Inc., Pawtucket, RI, 2010.

[18] Rodríguez G., Bonilla J. y Hernández J. J., "Numerical Modeling of Reinforced Concrete Continuous Deep Beams", Revista Ingeniería de Construcción Vol 31 No. 3 Diciembre de, 2016.

[19] Ihsan A. S. Al-Shaarbaf, Ahmed S. Ali, Abdulkhalik J. Abdulridha, "Experimental and Numerical Investigation of High Strength Reinforced Concrete Deep Beams with Web Openings under Repeated Loading”, AlNahrain Journal for Engineering Sciences (NJES) Vol.20 No.2, 2017, pp. 311-325.

[20] Rodríguez G., Bonilla J. y Hernández J. J., “Aplicación de la simulación numérica al estudio del comportamiento de vigas de gran peralto de hormigón armado", Revista Ingeniería Civil, 167, 2012, 101-116. 